\title{
Evolución financiera y perspectivas de la planta municipal en España
}

\section{Financial evolution and prospects of the municipal plant in Spain}

\author{
Óscar Romera Jiménez \\ Universidad Rey Juan Carlos \\ oscar.romera@urjc.es
}

\section{NOTA BIOGRÁFICA}

Doctor en Ciencias Económicas y Empresariales por la Universidad San Pablo CEU. Licenciado en Ciencias Económicas y Empresariales por la Universidad Complutense de Madrid. Máster en Dirección Económico-Financiera y Bancaria por IDE-CESEM. Programa en Liderazgo Público (PELP) por el Instituto de Empresa y programa en Liderazgo en Gestión Pública (PLPG) por IESE. Profesor asociado en el Departamento de Economía Financiera y Contabilidad de la Universidad Rey Juan Carlos. Desde noviembre de 2016, es director adjunto en el Gabinete del Ministro de Fomento.

\section{RESUMEN}

La planta municipal española viene caracterizada por ser una realidad en permanente adaptación a las circunstancias y excepcionalidades de su heterogénea estructura. Es necesario analizar el comportamiento de la Administración local en su plano normativo y financiero durante los últimos años; comprobar si se han conseguido los objetivos marcados en la cuestionada reforma local; ver en qué situación económicofinanciera está la planta local y qué necesidades y retos se plantean para el futuro de estos entes territoriales.

\section{PALABRAS CLAVE}

Evolución; hacienda local; heterogeneidad; indicadores; normativa.

\begin{abstract}
The Spanish municipal plant is characterized by being a reality in permanent adaptation to the circumstances and exceptional departure from its heterogeneous structure. It is necessary to analyse the behaviour of the Local Administration in its normative and financial level during the last years; to verify if the objectives marked in the questioned local reform have been achieved; to see in what economic-financial situation the local plant is and what needs and challenges are posed for the future of these territorial entities.
\end{abstract}

\section{KEYWORDS}

Evolution; heterogeneity; indicators; local finance; normative.

\section{SUMARIO}

1. INTRODUCCIÓN. 2. DIFERENTES PERSPECTIVAS EN EL DEBATE SOBRE LAS ENTIDADES LOCALES. 3. LA IMPORTANCIA DE LOS OBJETIVOS MARCADOS EN LA ADMINISTRACIÓN LOCAL. 4. METODOLOGÍA PARA LA IDENTIFICACIÓN DE PROGRAMAS DE INGRESO Y GASTO. 5. INDICADORES DEL CAMBIO DE LA SITUACIÓN ECONÓMICO-FINANCIERA DE LAS ENTIDADES LOCALES. 5.1. ACTUACIONES EMPRENDIDAS POR LAS ENTIDADES LOCALES DEL RÉGIMEN COMÚN. 5.2. MEDIDAS ESTABLECIDAS POR EL ESTADO. 6. CONCLUSIONES Y DISCUSIÓN. 7. BIBLIOGRAFÍA. 


\section{INTRODUCCIÓN}

La evolución financiera de las entidades locales en España muestra unos resultados diferentes a los obtenidos al inicio de la década. Las preocupaciones por el control del gasto público y mejora en la gestión presupuestaria nos ofrecen la modernización de las técnicas y procedimientos presupuestarios (Edo, 2011: 1). $Y$ tienen su origen en la crisis del Estado del bienestar cuyos impactos se evidencian en términos de cohesión social, políticas redistributivas y solidaridad (Fernández y Andrés, 2014). Las respuestas no se hacen esperar y ofrecen un escenario de necesaria convergencia dentro del ámbito europeo, no exento de complejidad: un mayor control de las remuneraciones de asalariados públicos; la determinación de salarios públicos y privados; el saneamiento de las finanzas públicas (Hernández de Cos y Pérez, 2015); una política comunitaria que impacta de manera más intensa en las políticas nacionales y sectoriales (Muñoz de Bustillo, 2002: 57).

El seguimiento en el desarrollo de la estructura del gasto público y su comparativa europea no es un elemento novedoso (Berdún, 2001: 235). Se analizan los fundamentos de la gobernanza multinivel del gasto público europeo (Martín Porras, 2013: 556); la importancia de la transparencia sobre la eficiencia y eficacia de las políticas públicas (Zapico, 2010: 239); la dimensión mediterránea bajo una perspectiva geoestratégica, política y económica en la planificación de los retos europeos (Escribano, 2011: 147); la importancia de la política de estabilidad presupuestaria en el marco de la Unión Europea (Domínguez y López, 2012); la importancia de la sociedad civil dentro de un marco europeo cada vez más cuestionado (García, 2016); un creciente interés la evaluación económica de las políticas públicas vinculadas a la eficiencia y la rentabilidad social del gasto (Albi y Onrubia, 2016); la formulación de presupuestos, la evaluación de gasto y la ejecución de políticas sectoriales en un entorno cada vez más descentralizado bajo una consolidación fiscal irreversible (Lago y Martínez-Vázquez, 2016); las limitaciones que impone el pago de la deuda (Centella, 2013); la incidencia del copago (Antoñanzas et al., 2014); la complejidad en la cohabitación en el cumplimiento del objetivo de déficit público y el mantenimiento del gasto social (Pérez, 2014).

Los resultados actuales de la planta municipal española no son fruto de la casualidad, ni ofrecen un camino despejado de dificultades y controversias. La existencia de una realidad territorial heterogénea, compleja, con un marcado inframunicipalismo y una consiguiente debilidad financiera (Arenilla et al.; 2014); la preocupación por la cohesión y bienestar social (Sánchez, A; Navarro, M; 2014), la exclusión social (Lorenzo, 2014), la redistribución de la renta y tamaño del sector público (Domínguez, 2014), la convergencia y desigualdad regional (Goerlich et al.; 2.011), el impacto de la economía sumergida (López del Paso, 2.013), la incidencia de las medidas de estabilidad presupuestaria en sistemas como la dependencia (Montserrat; 2015) o el debate sobre el origen de la desigualdad (Ayala; 2016) (Doménech; 2016) avalan un escenario complejo para toma de decisiones que no pueden esperar.

La política presupuestaria viene a reflejar la capacidad real para conseguir un objetivo perseguido. Es en su análisis y evaluación donde se identifican los resortes de la planificación y, por ende, de los resultados obtenidos como veremos.

\section{DIFERENTES PERSPECTIVAS EN EL DEBATE SOBRE LAS ENTIDADES LOCALES}

En los últimos años, el debate sobre las entidades locales no estuvo exento de rechazo respecto a los últimos cambios legislativos. Además, desde una perspectiva doctrinal la existencia de controversia parece evidente respecto al presente y futuro de la administración local (Domínguez; 2014); la preocupación por la reducción del déficit en las entidades locales (Crespo et al; 2010); el impacto de la integración europea en el actual modelo de gobernanza local donde la coexistencia entre los principios constitucionales y los retos derivados de los nuevos deberes municipales ofrecen un escenario complejo (Ruíz-Rico; 2016); el análisis de la arquitectura del sistema descentralizado en España y el papel que juegan las Comunidades Autónomas y las Corporaciones Locales (Pedraja y Pandiello, 2015); o los análisis en el plano normativo, institucional y competencial sobre el impacto en la autonomía local del nuevo entorno legislativo (Pérez; 2015).

Desde las aportaciones de (Muñoz; 1981), (Santamaría; 1982), (Parejo; 1981), (Martín; 1984) que abordaban la garantía institucional y la autonomía local como aquellas otras que incidían en la hacienda local (Baza; 1997), (Russines y Vázquez, 1985), (Zubiri; 1995). A las más recientes sobre la reforma local y el empobrecimiento de la democracia (Zafra; 2016), los retos actuales del gobierno local (Font i Llovet y Galán, 2014), los principios de la reforma local (Arenilla; 2014), sobre las nuevas oportunidades para el establecimiento como recurso ordinario municipal de las tasas municipales (Chico; 2010), la problemática de la 
financiación de los servicios públicos locales (Martínez; 2017), o la necesidad de abordar una reforma de la financiación local pendiente (Pedraja y Suárez, 2011) identifican dos vías generales de estudio: la normativa, fundamentalmente vinculada a las competencias municipales y por otro lado, la financiación asociada.

La reforma de la Administración local en tiempos de crisis económica y su influencia en los servicios públicos municipales (Chinchilla y Domínguez, 2015) ofrece dudas en su régimen de distribución competencial (Santamaría, 2014), la crítica abierta sobre las competencias «disponibles» (Jiménez; 2014) y su rechazo sobre los fines que persigue (Font i Llovet y Galán, 2014). Por otro lado, parece no completar la reforma de la financiación local efectuada en 2002 que proyectó el fortalecimiento del principio de suficiencia financiera y el incremento de la autonomía municipal como objetivos principales dentro del ámbito tributario (Aguerrea; 2002) (Pedraja; 2005). Tampoco ofrece una respuesta a los trabajos sobre participación de los entes locales (Pedraja; 2005) en los tributos del Estado (Pons; 2011) y de las Comunidades Autónomas (González; 2010).

A juicio de la doctrina, la reforma local no viene a dar solución a las necesidades del régimen local (Boix; 2017), ni cumple con las expectativas generadas (Merino; 2016) y su consolidación puede verse afectada ante el Tribunal Constitucional (Fuertes; 2016). Además, en el plano de la hacienda local existe una necesidad de una nueva reforma (Acín; 2016).

En definitiva, la planta municipal española supone un reto de permanente adaptación necesario para responder a las necesidades de los ciudadanos, no exento de dificultades, conforme a un doble plano normativo y financiero. Es necesario analizar la evolución de la Administración local en los últimos años para ofrecer el actual estado de situación de estos entes territoriales.

\section{LA IMPORTANCIA DE LOS OBJETIVOS MARCADOS EN LA ADMINISTRACIÓN LOCAL}

Es necesario analizar el comportamiento de la Administración local en su plano normativo y financiero durante los últimos años: (i) la comprobación de los objetivos marcados en la cuestionada reforma local y (ii) la observación del estado actual de la situación económico-financiera nos identificará las necesidades y retos a plantear para el futuro de la planta local.

Los principales objetivos de gestión recogidos en la Administración local desde el año 2012, dentro de un marco normativo, pasan por la clarificación de las competencias obligatorias con el fin de evitar duplicidades; la consolidación de un marco que asegure la gestión financiera de los municipios y una necesaria cooperación entre Administraciones; la adaptación del sector público empresarial local; el reforzamiento de los mecanismos de medición de los servicios y transparencia ciudadana; y una mayor profesionalización de la gestión pública. Desde una perspectiva financiera, recogen una respuesta ante una abrupta caída de los ingresos que hace necesario un ajuste del gasto para evolucionar hacia posiciones de equilibrio, al tiempo que ofrece una respuesta al excesivo recurso al endeudamiento.

Desde este planteamiento inicial, es necesario analizar el detalle de las actuaciones relacionadas con los objetivos anteriores. La identificación normativa y financiera nos ofrecerá una perspectiva definitiva cuya comparación con los análisis doctrinales relacionará (i) su estado actual con los objetivos marcados, (ii) al mismo tiempo que analizará la idoneidad de los estudios realizados en la materia.

\section{METODOLOGÍA PARA LA IDENTIFICACIÓN DE PROGRAMAS DE INGRESOS Y GASTOS}

Se identifican las siguientes bases de datos correspondientes a los programas de la administración territorial local (ayuntamientos, diputaciones de régimen común, diputaciones de régimen foral, consejos insulares, cabildos insulares, ciudades autónomas, áreas metropolitanas, comarcas, mancomunidades, agrupaciones de municipios y entidades locales menores) y detalle de la normativa vigente:

1. Los datos para la Entidades Locales se obtienen de la página web del Ministerio de Hacienda y Función Pública. En concreto, para el periodo 2010-2015 según obligaciones reconocidas netas en euros.

2. En relación a la normativa de aplicación se obtiene:

- Ley 7/85 Reguladora de las Bases de Régimen local.

- La Ley Orgánica 2/2012 de Estabilidad Presupuestaria y Sostenibilidad Financiera.

- La Ley 27/2013 de Racionalización y Sostenibilidad de la Administración Local. 
- La Orden EHA/3565/2008, de 3 de diciembre.

- La Orden HAP/2105/2012, de 1 de octubre.

3. Un catálogo de medidas de apoyo financiero:

- Mecanismos de pago a proveedores (3 fases en el periodo 2012-2013).

- Medidas extraordinarias Título II RDL 8/2013, de 28 de junio.

- Modificación de las condiciones de préstamos de la primera fase del mecanismo de pago a proveedores (ACDGAE 24-04-2014) con ampliación de periodos de amortización (10 años más) y carencia (2 años más) con rebaja mínima de tipo de interés; ampliación de periodo de carencia (1 año más) con rebaja intermedia de tipo de interés; rebaja máxima de tipo de interés.

- Refinanciación de operaciones con el Fondo de Proveedores; Ley 18/2014, de 15 de octubre.

- Definición del principio de prudencia financiera con reducción de la carga financiera.

- Fondo de financiación a Entidades Locales: RDL 17/2014, de 26 de diciembre.

- Financiación de la ejecución de sentencias firmes: Ley Orgánica 6/2015, de 12 de junio.

- Anticipos extrapresupuestarios y financiación de deudas con la AEAT y TGSS: RDL 10/2015.

4. Finalmente, se consultan los boletines estadísticos del personal al servicio de las Administraciones Públicas, el Instituto de Estadística, Banco de España y la Intervención General del Estado.

\section{INDICADORES DEL CAMBIO DE LA SITUACIÓN FINANCIERA DE LAS ENTIDADES LOCALES}

A pesar de la crítica sobre el fracaso de la reforma local (Boix; 2013) y su cuestionamiento en términos de falta de democracia (Zafra; 2016) la realidad del sector local se manifiesta como un conjunto de entidades saneadas financieramente. Es el único subsector del sector de administraciones públicas que presenta superávit, el cual cabe calificarlo de estructural en tanto se viene reproduciendo en los últimos cinco años en una franja que oscila entre el $0,5 \%$ y el $0,6 \%$ del PIB nacional, que presenta un nivel de deuda que se reduce progresivamente y unos niveles de liquidez que se incrementan. Estos datos vienen a cuestionar los estudios sobre las urgencias para la reforma de la ley de haciendas locales (Acín; 2016) y nos ofrecen una perspectiva más completa que la proyectada por (Suárez; 2003) sobre corresponsabilidad fiscal local. En conjunto, la interrelación entre estas tres magnitudes es evidente, al igual que su evolución positiva.

Profundizando sobre la situación financiera de las entidades locales podemos concluir que, en conjunto presentan superávit, con criterios de contabilidad nacional, del $0,64 \%$ del PIB en 2016 . Se trata de una posición financiera global consolidada y se deduce que este superávit en términos PIB duplica al que presentaron en 2012, año a partir del que cambia sustancialmente la situación financiera de las entidades locales, y que, en términos absolutos, supone un importe superior en más del doble al presentado en 2012: 7.083 millones $€$, en 2016, frente a 3.307 millones $€$, en 2012. Éste resultado, al igual que los siguientes, se enmarcan dentro una reforma local auspiciada en el año 2013 y del conjunto de medidas financieras y de gasto habilitadas a los efectos. En este sentido, las dudas sobre la planificación económico-financiera de los municipios (Santamaría; 2014) quedarían descartadas.

En 2011, el déficit del conjunto de entidades locales era de -8.506 millones $€$, el $-0,79 \%$ del PIB. En el período 2012-2016 dichas entidades han mejorado su posición financiera en 15.589 millones $€$. Entre 2010 y 2015, el número de entidades con saldos no financieros negativos se ha reducido a la tercera parte, y el de entidades que tienen saldos positivos se ha incrementado en un $51 \%$. Mientras que, en 2010 , el $48 \%$ de las entidades presentaban saldos no financieros negativos, en 2015 los presentaban el 18\%. En términos de sostenibilidad financiera, éstos datos expresan un línea argumental que difiere a la descrita por (Font i Llovet y Galán, 2012). Ver cuadro núm. 1.

En relación a la aportación de (Zafra et al; 2010) sobre la influencia de determinados factores económico-financieros y sociales en la variabilidad del nivel de endeudamiento cabe indicar que la deuda de las entidades locales a 31 de diciembre de 2015 se encuentra en niveles del año 2010, pero es preciso reseñar que en la deuda de 2015 se incluye la correspondiente al mecanismo de pagos a proveedores. En este sentido, es en el año 2012 donde se alcanza un máximo por efecto del mecanismo de pagos a proveedores, pero a partir de 2013 se inicia un descenso a un ritmo anual medio del 7\% (ver cuadro núm. 2). Por lo tanto, se plantearía la necesidad de revisar la ponderación sobre la influencia de elementos externos frente a las magnitudes financieras internas contempladas. 
La reforma del artículo 135 de la Constitución española y la subordinación de la deuda pública a los principios de estabilidad presupuestaria y sostenibilidad financiera (Mochón; 2012) trae consecuencias que se identifican, a 31 de diciembre de 2015, en un nivel de deuda que se sitúa en el 3,3\% del PIB nacional, en términos absolutos en 35.131 millones $€$, y a 31 de diciembre de 2016 se sitúa en el 2,9\% del PIB (32.094 millones $€$ ), por debajo del objetivo fijado para 2020 en la Ley Orgánica de Estabilidad Presupuestaria y Sostenibilidad Financiera. Las modificaciones incorporadas afectan a la gestión económico financiera de las entidades locales en materia de endeudamiento (Calvo; 2014). Una evolución del endeudamiento que presenta un carácter condicionado por la nueva normativa vigente (Ruiz; 2017) y que es motivo de preocupación también en Francia, como bien describe (Delaunay; 2014).

En relación al remanente de tesorería para gastos generales de las entidades locales es de 8.676,3 millones $€$, cuando en 2010 fue de $-1.078,0$ millones $€$ y en 2011 empeoró hasta llegar a -2.760,5 millones $€$. Simplemente para visualizar el efecto de una medida que ha resultado fundamental como la correspondiente al mecanismo de pagos a proveedores cabe observar cómo el citado remanente pasó de aquel valor negativo de 2011 a un valor positivo de 4.357,4 millones $€$, en 2012, debido a la sustitución de deuda comercial por deuda financiera en este ejercicio (González; 2014).

La situación expuesta, consecuencia de las medidas para garantizar la estabilidad presupuestaria (Ortega; 2012) ha permitido que el período medio de pago a proveedores de las entidades locales incluidas en el modelo de cesión de impuestos estatales se haya situado en diciembre de 2016 en 45,44 días. A su vez, los ayuntamientos incluidos en el modelo de variables presentaron en diciembre de 2016 un periodo medio de pago de 40,84 días. La situación anterior no significa que todas las entidades locales estén saneadas financieramente. Esto se puede predicar de las diputaciones provinciales, consejos y cabildos insulares (Romera; 2016). En el caso de los ayuntamientos, en un colectivo tan amplio con 8.125 entidades, se encuentran algunas entidades que no han conseguido reconducir su situación financiera, fundamentalmente porque no han adoptado medidas discrecionales activas de política fiscal o porque no se han acogido a aquellas otras que, con carácter extraordinario, se han aprobado desde el Estado (Carpio; 2015).

\subsection{Actuaciones emprendidas por las entidades locales del régimen común}

El impacto de las modificaciones que afectan a la gestión económico-financiera de las entidades locales (Calvo; 2014) se puede medir en términos de contención del gasto no financiero en un 7,8\%. Entre 2011 y 2015 las entidades locales redujeron el gasto no financiero en 4.082,7 millones $€$. La reducción del gasto se ha focalizado en el gasto de inversión real (reducción de 2.813,8 millones $€$ ), que se ha reducido el $32 \%$ en ese período y en los gastos de personal (reducción de 719,7 millones $€$ ) que se han reducido un $3,9 \%$. En este sentido, la búsqueda de la eficiencia y control (Ortega; 2016), las dudas sugeridas por (Boix; 2017) o la ineficacia de las medidas contempladas en la reforma local (Merino; 2016) quedan descartadas. (ver cuadro núm. 1).

CUADRO 1. EVOLUCIÓN DE GASTOS DE AYUNTAMIENTOS Y DIPUTACIONES. PERIOdO 2011-2015. TASAS DE VARIACIÓN INTERANUAL

\begin{tabular}{clccccc}
\hline Cap. & \multicolumn{1}{c}{ Gastos } & $\mathbf{2 0 1 2 / 2 0 1 1}$ & $\mathbf{2 0 1 3 / 2 0 1 2}$ & $\mathbf{2 0 1 4 / 2 0 1 3}$ & $\mathbf{2 0 1 5 / 2 0 1 4}$ & Total \\
\hline 1 & Gastos de personal & $-10,06$ & 2,12 & 1,11 & 3,47 & $-3,91$ \\
\hline 2 & $\begin{array}{l}\text { Gastos corrientes en bienes y } \\
\text { servicios }\end{array}$ & 1,74 & $-7,87$ & 2,04 & 0,91 & $-3,49$ \\
\hline 3 & Gastos financieros & 30,09 & 9,16 & $-2,66$ & $-41,81$ & $-19,56$ \\
\hline 4 & Transferencias corrientes & $-0,16$ & 2,73 & 2,04 & 5,67 & 10,59 \\
\hline 5 & Fondo de contingencia & & & & \\
\hline & Operaciones Corrientes & $-3,00$ & $-1,75$ & 1,46 & 1,12 & $-2,23$ \\
\hline 6 & Inversiones reales & $-39,13$ & $-16,39$ & 17,06 & 13,45 & $-32,41$ \\
\hline 7 & Transferencias de capital & $-36,91$ & $-7,59$ & 35,25 & 1,35 & $-20,09$ \\
\hline
\end{tabular}




\begin{tabular}{llrrrrr}
\hline Cap. & \multicolumn{1}{c}{ Gastos } & $\mathbf{2 0 1 2 / 2 0 1 1}$ & $\mathbf{2 0 1 3 / 2 0 1 2}$ & $\mathbf{2 0 1 4 / 2 0 1 3}$ & $\mathbf{2 0 1 5 / 2 0 1 4}$ & Total \\
\hline & Operaciones de Capital & $-38,77$ & $-14,91$ & 20,40 & 10,96 & $-30,39$ \\
\hline \multirow{2}{*}{8} & Operaciones no Financieras & $-\mathbf{1 0 , 1 4}$ & $\mathbf{- 3 , 5 4}$ & $\mathbf{3 , 7 4}$ & $\mathbf{2 , 4 9}$ & $\mathbf{- 7 , 8 5}$ \\
\hline 9 & Activos financieros & 224,26 & $-53,20$ & $-10,93$ & 67,15 & 125,94 \\
\hline & Pasivos financieros & 32,45 & 19,12 & 56,37 & $-19,54$ & 98,50 \\
\hline & Operaciones Financieras & $\mathbf{4 7 , 9 5}$ & $\mathbf{6 , 3 1}$ & $\mathbf{5 1 , 1 2}$ & $\mathbf{- 1 5 , 5 6}$ & $\mathbf{1 0 0 , 7 2}$ \\
\hline & Total gastos & $\mathbf{- 6 , 8 0}$ & $\mathbf{- 2 , 6 5}$ & $\mathbf{8 , 4 5}$ & $\mathbf{- 0 , 0 2}$ & $\mathbf{- 1 , 6 2}$ \\
\hline
\end{tabular}

Fuente: elaboración propia a partir de datos del Ministerio de Hacienda y Función Pública

Además, en referencia a los ingresos no financieros, el impacto del carácter condicionado en la gestión económico-financiera local descrito por (Monchón; 2015) queda recogido con un incremento del 6,3\% y vuelve a cuestionar las aportaciones de (Font i Llovet y Galán; 2012), (Boix; 2017), (Merino; 2016). Entre 2011 y 2015 las entidades locales incrementaron su ingreso no financiero en 3.222,3 millones $€$, siendo los más relevantes los impuestos directos con un aumento de $3.595,5$ millones de euros (el $21,2 \%$ en ese período) y las transferencias corrientes, con un incremento de $1.611,8$ millones $€$, crecimiento del $8,8 \%$ en ese período. (ver cuadros núm. 2 y núm. 3)

CUADRO 2. EVOLUCIÓN DE INGRESOS DE AYUNTAMIENTOS Y DIPUTACIONES. PERIODO 2011-2015. TASAS DE VARIACIÓN INTERANUAL

\begin{tabular}{llrrrrr}
\hline Cap. & \multicolumn{1}{c}{ Ingresos } & $\mathbf{2 0 1 2 / 2 0 1 1}$ & $\mathbf{2 0 1 3 / 2 0 1 2}$ & $\mathbf{2 0 1 4 / 2 0 1 3}$ & $\mathbf{2 0 1 5 / 2 0 1 4}$ & Total \\
\hline 1 & Impuestos directos & 7,25 & 6,05 & 4,09 & 2,39 & 21,22 \\
\hline 2 & Impuestos indirectos & $-8,40$ & 8,88 & $-6,70$ & 7,95 & 0,45 \\
\hline 3 & $\begin{array}{l}\text { Tasas, precios públicos y otros } \\
\text { ingresos }\end{array}$ & $-1,86$ & $-1,05$ & $-0,59$ & $-2,26$ & $-5,64$ \\
\hline 4 & Transferencias corrientes & $-0,41$ & 6,25 & $-0,19$ & 3,03 & 8,81 \\
\hline 5 & Ingresos patrimoniales & $-16,69$ & $-0,42$ & 13,22 & $-23,42$ & $-28,08$ \\
\hline & Operaciones Corrientes & $\mathbf{1 , 2 5}$ & $\mathbf{4 , 8 3}$ & $\mathbf{1 , 8 9}$ & $\mathbf{1 , 9 6}$ & $\mathbf{1 0 , 2 6}$ \\
\hline 6 & Enajenación de inversiones reales & $-18,30$ & $-28,04$ & 20,93 & 16,77 & $-16,98$ \\
\hline 7 & Transferencias de capital & $-44,37$ & $-7,58$ & 13,74 & $-6,18$ & $-45,14$ \\
\hline & Operaciones de Capital & $-\mathbf{4 1 , 4 5}$ & $\mathbf{- 1 0 , 7 8}$ & $\mathbf{1 4 , 6 5}$ & $\mathbf{- 3 , 1 3}$ & $-\mathbf{4 1 , 9 8}$ \\
\hline & Operaciones no Financieras & $\mathbf{- 2 , 0 1}$ & $\mathbf{4 , 1 2}$ & $\mathbf{2 , 3 9}$ & $\mathbf{1 , 7 4}$ & $\mathbf{6 , 2 8}$ \\
\hline 8 & Activos financieros & 122,46 & $-35,26$ & $-0,69$ & 87,05 & 167,56 \\
\hline 9 & Pasivos financieros & $\mathbf{3 0 2 , 7 0}$ & $\mathbf{- 7 7 , 9 0}$ & $\mathbf{5 0 , 4 4}$ & $-16,21$ & 12,19 \\
\hline & Operaciones Financieras & $\mathbf{2 8 8 , 9 8}$ & $\mathbf{- 7 6 , 0 4}$ & $\mathbf{4 4 , 4 2}$ & $\mathbf{- 7 , 8 6}$ & $\mathbf{2 4 , 0 1}$ \\
\hline & Total ingresos & $\mathbf{1 1 , 8 8}$ & $\mathbf{- 9 , 1 8}$ & $\mathbf{4 , 2 3}$ & $\mathbf{1 , 1 5}$ & $\mathbf{7 , 1 2}$ \\
\hline
\end{tabular}

Fuente: elaboración propia a partir de datos del Ministerio de Hacienda y Función Pública

En definitiva, del conjunto de las políticas de gasto e ingreso público, las entidades locales han incrementado su capacidad de financiación en 7.305,1 millones $€$, siguiendo criterios presupuestarios (sin ajustes de contabilidad nacional). De ese importe, 5.693,3 millones $€$ se han generado por actuaciones propias de las corporaciones locales y 1.611,8 millones $€$ por políticas adoptadas por otras administraciones públicas, 
fundamentalmente por el Estado. En este sentido, las aportaciones realizadas por (Boix; 2017), (Merino; 2016), (Font i Llovet y Galán; 2012), (Zafra; 2016) abordan diferentes perspectivas que no incorporan los objetivos marcados en términos de estabilidad presupuestaria y sostenibilidad financiera. Y es en el cumplimiento de éstos objetivos donde se garantiza la viabilidad de las propuestas que indican.

CUADRO 3. DESGLOSE INGRESOS DE AYUNTAMIENTOS. LIQUIDACIÓN PRESUPUESTOS 2015

\begin{tabular}{lrr}
\hline Conceptos de ingresos & $\begin{array}{c}\text { Importe } \\
\text { (miles de } € \text { ) }\end{array}$ & $\begin{array}{c}\% \text { sobre } \\
\text { ingreso total }\end{array}$ \\
\hline IBI & 13.379 .132 & $27,38 \%$ \\
\hline IVTM & 2.198 .768 & $4,50 \%$ \\
\hline IIVTNU & 2.615 .518 & $5,35 \%$ \\
\hline IAE & 1.406 .227 & $2,88 \%$ \\
\hline Resto Imp. Directos & 440.966 & $0,90 \%$ \\
\hline ICIO & 528.927 & $1,08 \%$ \\
\hline Resto Imp. Indirectos & 864.528 & $1,77 \%$ \\
\hline Tasas & 5.042 .423 & $10,32 \%$ \\
\hline Precios públicos & 598.995 & $1,23 \%$ \\
\hline Resto Capítulo 3 & 2.011 .991 & $4,12 \%$ \\
\hline Ingresos Patrimoniales (caps. 5 y 6) & 1.239 .601 & $2,54 \%$ \\
\hline Transferencias corrientes de la AGE & 10.678 .830 & $21,86 \%$ \\
\hline Transferencias corrientes de las CC. AA. & 2.982 .070 & $6,10 \%$ \\
\hline Transferencias corrientes de las Diputaciones & 708.356 & $1,45 \%$ \\
\hline Transferencias corrientes otros sectores & 301.930 & $0,62 \%$ \\
\hline Transferencias de capital & 1.519 .765 & $3,11 \%$ \\
\hline Ingresos no financieros & $\mathbf{4 6 . 5 1 8 . 0 2 6}$ & $\mathbf{9 5 , 2 1 \%}$ \\
\hline Ingresos Financieros (caps. 8 y 9) & 2.341 .438 & $4,79 \%$ \\
\hline Total ingresos & $\mathbf{4 8 . 8 5 9 . 4 6 5}$ & $\mathbf{1 0 0 , 0 0 \%}$ \\
\hline
\end{tabular}

Fuente: elaboración propia a partir de datos del Ministerio de Hacienda y Función Pública

Los resultados en el ejercicio 2015 en perspectiva comparada: los municipios tienen una importante autonomía financiera, en tanto el $62 \%$ de sus ingresos proceden de fuentes de financiación propia (los tributos propios, que representan el $59,5 \%$ del ingreso total, e ingresos patrimoniales, el $2,5 \%$ del ingreso total), el $33 \%$ proceden de transferencias de otras administraciones públicas y el $5 \%$ del recurso al endeudamiento; por el contrario, las diputaciones provinciales presentan una fuerte dependencia financiera de otras administraciones públicas, fundamentalmente del Estado: el $21 \%$ de sus ingresos proceden de recursos propios, el $68 \%$ proceden de transferencias de otras administraciones públicas y el $11 \%$ del recurso al endeudamiento; los cabildos insulares canarios presentan una estructura financiera parecida a la de los municipios y los consejos insulares de Baleares parecida a la de las diputaciones provinciales. Las diputaciones forales presentan una estructura financiera peculiar como consecuencia del régimen de concierto con el País Vasco. A las anteriores entidades locales, que están reconocidas en nuestra Constitución, habría que añadir aquellas otras que ha incorporado la legislación básica de régimen local como son las mancomunidades, comarcas, áreas metropolitanas, mancomunidades, agrupaciones de municipios o entidades de ámbito territorial inferior al municipio (ver cuadro núm. 4). 
CUADRO 4. ESTRUCTURA DEL INGRESO DE LAS ENTIDADES LOCALES. DATOS DE LIQUIDACIONES DE PRESUPUESTOS PARA EL AÑO 2015

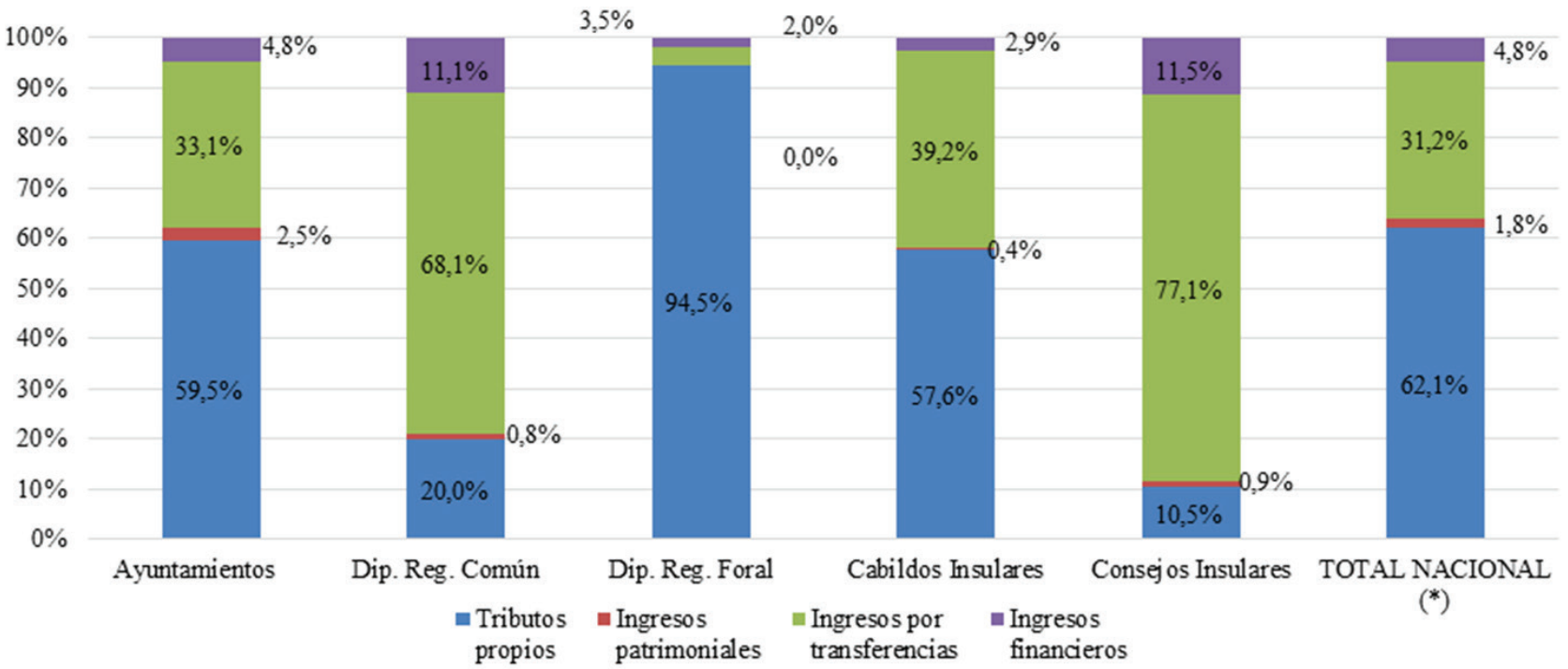

Fuente: elaboración propia a partir de datos del Ministerio de Hacienda y Función Pública.

En relación a la reducción del sector público local, desde el año 1996 hasta 2009 se produjo un incremento progresivo de este sector; sin embargo, desde el año 2010 se aprecia un cambio de tendencia que se refleja en una bajada de un $-28,2 \%$ en el número de entes de 2009 a 2016 , situándose, en cuanto a su número, en niveles análogos a los de 1999. Sólo entre 2011 y 2016 se ha reducido en un $21 \%$ el sector público local, pasando de 5.562 entidades dependientes a 31 de diciembre de 2011 a 4.406 entidades en la misma fecha de 2016. Esta evolución debe enmarcarse en los ámbitos ya tratados desde un punto de vista normativo (Carpio; 2015) y financiero (Lozano; 2012) en contraposición a una perspectiva no seguida en las aportaciones de (Robles; 2014), (Merino; 2016) o (Zafra; 2016). (ver cuadro núm. 5)

CuAdro 5. eVOlución entes SECTOR PÚBlico local. Periodo 1996-2016

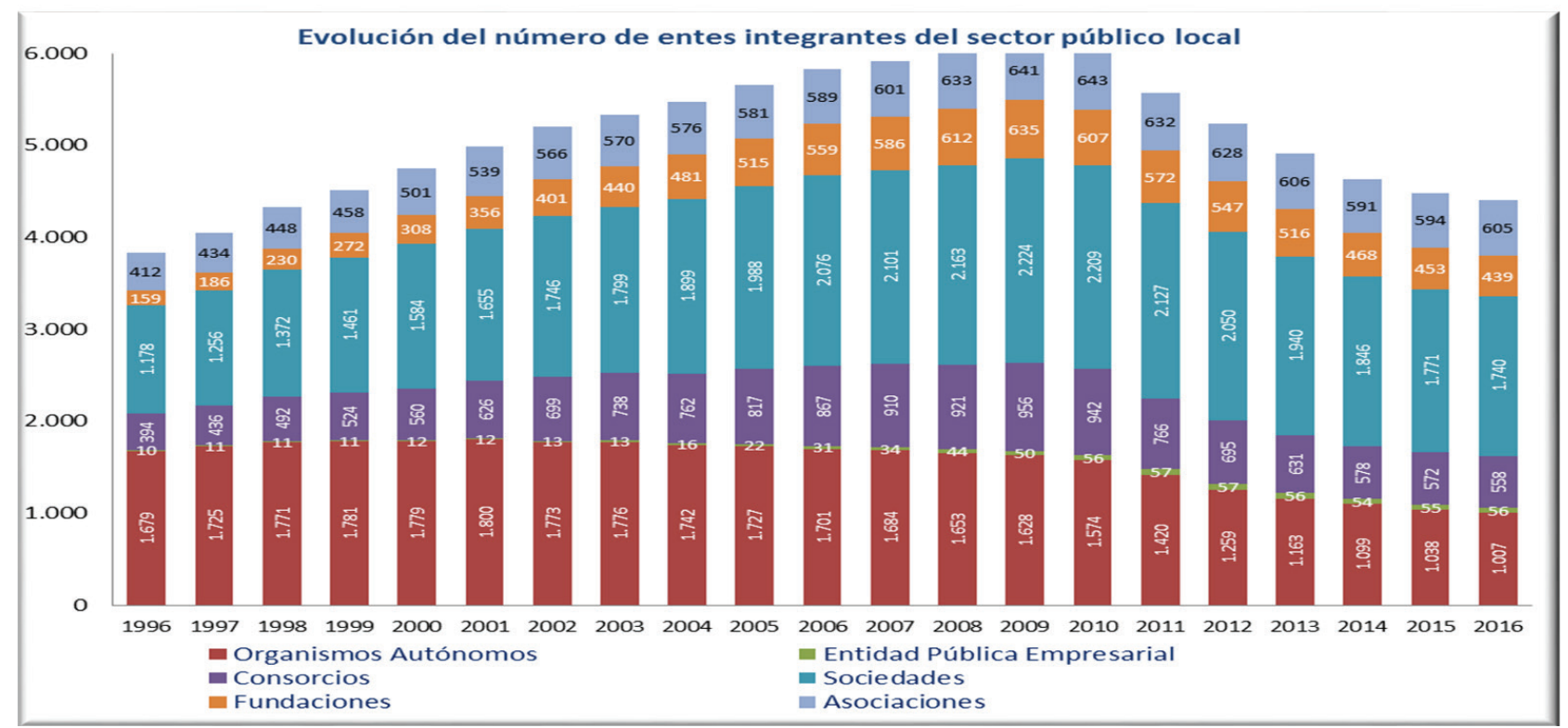

Fuente: elaboración propia a partir de datos del Ministerio de Hacienda y Función Pública 


\subsection{Medidas establecidas por el Estado}

El resumen del catálogo de medidas de carácter estructural y financiero, bien estableciendo mecanismos de financiación instrumentados en operaciones financieras (Lozano; 2012), bien aprobando medidas en el ámbito de la participación en tributos del Estado (Mochón; 2012) pasa por la implantación de medidas de carácter estructural en torno a la Ley Orgánica de Estabilidad Presupuestaria y Sostenibilidad Financiera y a la Ley de Racionalización y Sostenibilidad de la Administración Local, que reformó el régimen local de modo que el ámbito competencial y la actividad de prestación de servicios fuese congruente con el escenario que se plantea en aquella Ley Orgánica y con el cumplimiento de las reglas fiscales (Algarra y Romera; 2015).

Por lo que se refiere a la Ley Orgánica de Estabilidad Presupuestaria y Sostenibilidad Financiera, la definición de los principios de estabilidad y sostenibilidad financiera (Mochón; 2015) y la relación con el control tanto de la deuda financiera (Angoitia; 2014) como de la comercial (González; 2014); dando un impulso decisivo al principio de transparencia que se completó con la Orden HAP/2105/2012, de 1 de octubre, en la que se detalla la información que deben suministrar las entidades locales y su periodicidad (Campos; 2016); estableciendo reglas fiscales que son de aplicación a todas y a cada una de las administraciones públicas (Calvo; 2014): (i) el objetivo de estabilidad presupuestaria, que en el caso de las entidades locales se fija en el $0,0 \%$ del PIB, (ii) el objetivo de deuda pública, que en el caso de las entidades locales es del $3,0 \%$ del PIB en 2016, del 2,9\% en 2017, del 2,8\% en 2018 y del 2,7\% en 2019, (iii) la regla de gasto, que es común para todas las administraciones públicas, de modo que el gasto computable de cada una de ellas en cada ejercicio respecto del inmediato anterior no puede incrementarse por encima de la tasa de variación del PIB nominal previsto y que se ha concretado en el $1,8 \%$ en $2016 ; 2,1 \%$ en $2017 ; 2,3 \%$ en 2018 y $2,5 \%$ en 2019.

La regla general de destinar el superávit presupuestario para reducir el nivel de deuda pública. Y la especial, para las entidades locales que estén saneadas y presenten un período medio de pago a proveedores no superior al plazo máximo que establece la normativa de morosidad, para destinar el superávit a cancelar obligaciones de pago con proveedores y a financiar inversiones financieramente sostenibles, sin que esto último pueda implicar que las entidades locales incurran en déficit al final del ejercicio en el que se ejecuten aquéllas (Ruiz; 2017). Con ello se ha tratado de evitar la reproducción de situaciones bastante habituales con las que se habían encontrado en tiempos recientes los municipios de asunción de proyectos de inversión que generaban unos elevados gastos corrientes y, potencialmente, déficit difíciles de corregir (Crespo et al.; 2010).

La Ley de Racionalización y Sostenibilidad de la Administración Local que integra en el régimen local elementos de sostenibilidad financiera y de garantía de prestación eficiente de los servicios por parte de las entidades locales (Ortega; 2016), con una controversia sobre el principio de autonomía local para la gestión de sus propios intereses (Zafra; 2016), (Font i Llovet y Galán; 2012), (Robles; 2014), (Pérez; 2015), finalmente, que es superada en las sentencias del Tribunal Constitucional (Fuertes; 2016) ante los recursos de inconstitucionalidad interpuestos por las Comunidades Autónomas de Extremadura, Andalucía y Asturias y por más de 50 diputados pertenecientes a diversos grupos parlamentarios.

Por otro lado, frente a las aportaciones de (Boix; 2017), (Merino; 2016), (Robles; 2014) la Ley de Racionalización y Sostenibilidad de la Administración Local incide en la estructura financiera de las entidades locales al (i) establecer un mapa competencial con mayor claridad que el anteriormente existente, distinguiendo entre competencias propias, competencias delegadas y competencias que no se encuadran en ninguno de esos grupos, pero que sólo se pueden ejecutar si no lo están realizando otras administraciones públicas (no duplicidad de la actividad administrativa) y si son sostenibles financieramente para el conjunto de la respectiva hacienda local. Esta distribución de competencias ha sido considerada respetuosa con la autonomía local y declarada constitucional por el Tribunal Constitucional; (ii) la prestación de los servicios por las entidades locales debe realizarse de la forma más eficiente posible, para lo que se definió una magnitud que puede servir de referencia, el coste efectivo de los servicios. Se trata de evitar que la elección de la forma de prestación de servicios atienda a criterios políticos sin una fundamentación técnica y económica solventes; (iii) la garantía de la prestación de servicios públicos potenciando el papel de las diputaciones provinciales para asegurar dicha prestación sobre todo en lo que se refiere a los servicios esenciales y a los municipios de población inferior a 20.000 habitantes, pudiendo prestarse por ellas mismas mediante formas consorciadas o mancomunadas y siempre que los municipios concernidos lo acepten; (iv) el impulso de las actuaciones de control, modificando algunos preceptos del texto refundido de la Ley reguladora de las Haciendas Locales en materia de control interno, reparos y resolución de discrepancias, potenciando, a su vez, la función de fiscalización que compete a los interventores de la administración local; ( $\mathrm{v}$ ) y finalmente, el establecimiento de normas muy concretas que permitan alcanzar una dimensión adecuada del sector público de cada una de las entidades locales. 
Desde el año 2012 se han venido adoptando medidas para proveer de mayores recursos o de un mayor margen de maniobra financiero a las entidades locales. En el ámbito tributario, la medida más relevante se incluyó en el conjunto que reguló el Real Decreto-ley 20/2011, de 30 de diciembre, de medidas urgentes en materia presupuestaria, tributaria y financiera para la corrección del déficit público, que posibilitó la aplicación de manera transitoria y excepcional durante los ejercicios 2012 y 2013 para los inmuebles urbanos de un incremento del tipo impositivo del IBI, de una manera progresiva, atendiendo a la antigüedad de la revisión catastral, y por lo tanto, a su adecuación al mercado (Ruiz; 2017). El incremento de recaudación para las Entidades Locales se ha situado en 988 millones $€$ en 2012, respecto de 2011, y en 1.487 millones $€$ en 2013, también respecto de 2011.

La medida de incremento del tipo impositivo del IBI se ha prorrogado para los años 2014 y 2015 , mediante la Ley 16/2013, de 29 de octubre, por la que se establecen determinadas medidas en materia de fiscalidad medioambiental y se adoptan otras medidas tributarias y financieras. En consecuencia, los municipios han mantenido hasta el año 2015 el nivel de ingresos incrementados con la medida que entró en vigor en 2012. Asimismo, en relación con el IBI, se ha establecido un procedimiento de regularización de las unidades catastrales «ocultas» y de aplicación de coeficientes sobre el valor catastral (Alonso; 2013).

En relación a la participación en tributos del Estado y en el marco de actuación señalado por (Arrieta; 2010) (Martín; 2011), se aprueba (i) la articulación de un anticipo del 50\% de la liquidación definitiva de la participación en tributos del Estado correspondiente a 2010 (calculada en 2012), de modo que se adelantaron recursos a las entidades locales por un importe de 991 millones de euros; se habilita (ii) la posible ampliación de 60 a 120 mensualidades del período de reintegro de los saldos deudores que resultaron, a cargo de las entidades locales, en las liquidaciones de 2008 y 2009; (iii) a las entidades locales a las que se aplica la ampliación a 120 mensualidades pudieron en 2014 solicitar una nueva ampliación hasta 240 mensualidades computadas a partir de enero de 2012 o de 204 computadas desde enero de 2015; y se establece (iv) la posibilidad de ampliar (de un máximo de 3 años) hasta 120 mensualidades los reintegros de las liquidaciones negativas correspondientes a 2013, si bien se han debido compensar con los saldos a ingresar que resultaron de la liquidación del año 2014.

Como resultado de la aplicación de los modelos de participación en tributos del Estado, cabe significar que, si consideramos todos los conceptos de participación así como los reintegros derivados de liquidaciones negativas la financiación se ha incrementado (considerando las dotaciones contenidas en los Presupuestos Generales del Estado) un 22,6\% entre 2011 y 2017, pasando de 14.438,93 a 17.697,02 millones $€$.

Como señalan (Lozano y Vázquez, 2012) y dentro del marco de la deuda comercial, se define un mecanismo de pagos a proveedores en febrero de 2012 (RDL 4/2012, de 24 de febrero), con una segunda fase en febrero de este año (RDL 4/2013, de 22 de febrero) y otra tercera en junio (RDL 8/2013, de 28 de junio). Inicialmente, en una primera fase, se trataba de financiar las deudas derivadas de contratos de obras, suministros y servicios. Pero se amplió en sus ámbitos objetivo y subjetivo en las fases segunda y tercera. Con este mecanismo se habilita la posibilidad de convertir la deuda comercial vencida, líquida y exigible, en deuda financiera a largo plazo, amortizable en 10 años con los dos primeros de carencia de amortización del principal. La aplicabilidad de esta medida estaba sujeta a la aprobación de un plan de ajuste y su valoración favorable por parte del Ministerio de Hacienda y Administraciones Públicas. Los resultados beneficiaron a 3.964 entidades locales, en alguna de las fases citadas, y atendido el pago de 2.097.357 facturas de 123.733 proveedores, por importe total de $11.563,4$ millones $€$, lo que ha permitido salvar y dar viabilidad a muchas PYMES y autónomos abocados a la quiebra ante el impago de las Administraciones.

En junio de 2014 se posibilita la reestructuración de los préstamos formalizados con el Fondo de Proveedores, en la primera fase del mecanismo de pagos a proveedores, que beneficia a 1.299 entidades locales con una deuda total con el Fondo de Proveedores de 7.364,5 millones $€$, y que pudieron, según los casos, ampliar el período de amortización de 10 a 20 años y el de carencia en 2 años más con una rebaja mínima del tipo de interés de 41 puntos básicos, o ampliar el período de carencia en un año más con una rebaja del tipo de interés de 131 puntos básicos, o no modificar ninguno de esos períodos, pero rebajar el tipo de interés en 140 puntos básicos (ver cuadro núm. 5). Estas medidas supondrán una inyección de liquidez, según las previsiones del Ministerio de Hacienda y Función Pública hasta el año 2022, de 1.637 millones $€$. En el segundo semestre de ese mismo año, se autorizó la refinanciación de los préstamos formalizados con el FFPP mediante el Real Decreto-ley 8/2014, de 4 de julio, convalidado mediante la Ley 18/2014, de 15 de octubre, de modo que las entidades locales pudieron acogerse a las mejores condiciones del mercado financiero. 
Además, es preciso tener en cuenta que se aprobó la Ley 25/2013, de 27 de diciembre, de Factura electrónica y registro contable de facturas en el sector público (Calvo; 2014), por la que se declaró la obligatoriedad de utilizar la factura electrónica desde, 15 de enero de 2015, debiendo contar todas las administraciones públicas con un punto general de entrada de facturas electrónicas (FACe) para que los proveedores puedan presentarlas.

\section{CUADRO 6. EVOLUCIÓN DEL TIPO DE INTERÉS DE PRÉSTAMOS CON EL FONDO DE ENTIDADES LOCALES.} PERIODO 2012-2016

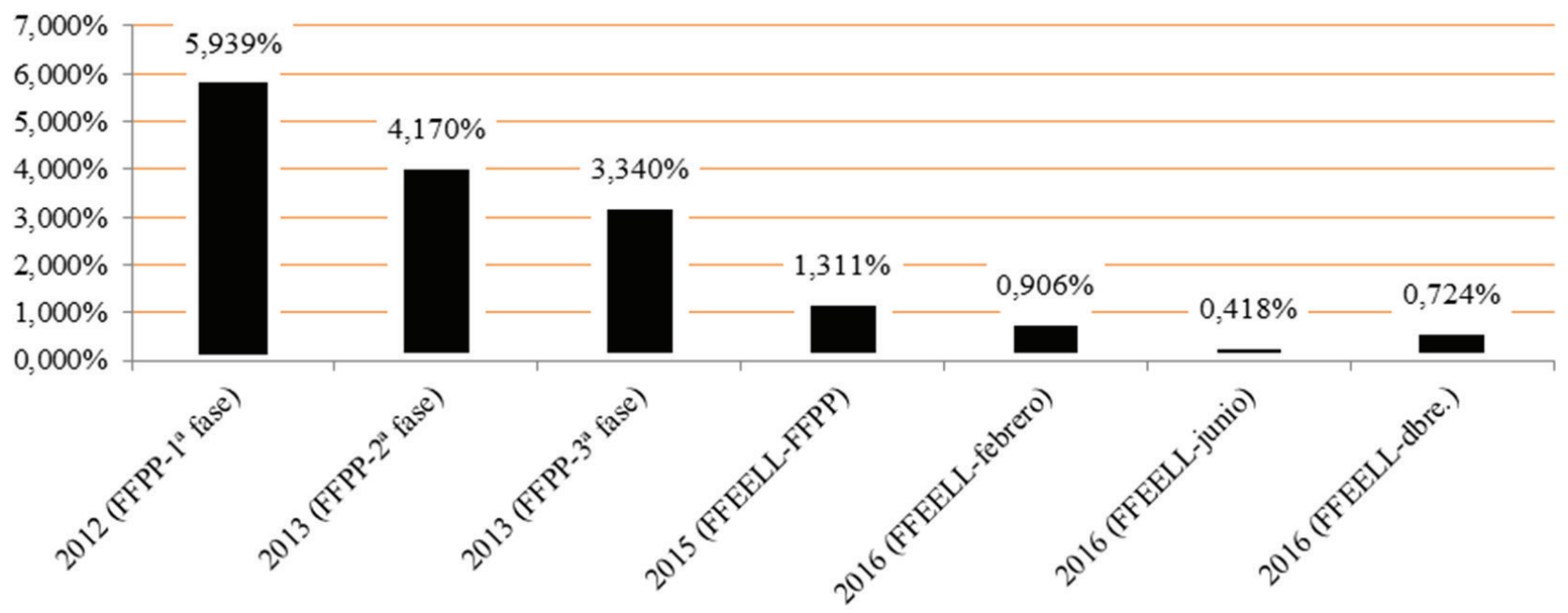

Fuente: elaboración propia a partir de datos del Ministerio de Hacienda y Función Pública.

En el marco de la deuda financiera, como señala (Carpio; 2015) se ha definido en 2014 (RDL 17/2014, de 26 de diciembre) por vez primera el principio de prudencia financiera como un principio básico aplicable en el régimen de endeudamiento de las entidades locales, de modo que sólo pueden formalizar préstamos, tanto a corto como a largo plazo, a costes financieros que no superen los límites máximos que fije la Secretaría General del Tesoro y Política Financiera. Los motivos por los que se incluyó ese principio se basan en la existencia de una fuerte reducción de la competencia bancaria y la consiguiente limitación en el acceso al mercado de capitales; la escasa capacidad de negociación de las corporaciones locales; el importante grado de heterogeneidad de precios entre entidades con estructuras financieras análogas; e impedir la inclusión de cláusulas abusivas en contratos de préstamos y derivados.

Esta medida supondrá una reducción considerable de los gastos financieros, con la consiguiente mejora del saldo no financiero de las entidades locales. Así, la evolución de los tipos de interés aplicables a los préstamos formalizados con el Fondo de Proveedores y ahora con el Fondo de Financiación a Entidades Locales han pasado del $5,939 \%$ que se aplicó en las operaciones formalizadas en la primera fase del mecanismo de pagos a proveedores, en 2012, al 1,311\% que se ha fijado en 2015. Asimismo, a los préstamos formalizados con el Fondo de Financiación a Entidades Locales en diciembre de 2016 se les ha aplicado un tipo de interés del $0,724 \%$.

Sobre medidas específicas de carácter extraordinario a favor de ayuntamientos con problemas financieros estructurales y estableciendo una necesaria atención a la diversidad tipológica de los municipios (Navarro; 2016) conforme a su autonomía y suficiencia financiera (Pablos; 2015) se establece en el Título II del RDL 8/2013 medidas extraordinarias de apoyo financiero a municipios con problemas. Según datos del Ministerio de Hacienda y Función Pública, solicitan esta medida 101 entidades, de las que finalmente 75 se han beneficiado; en septiembre de 2015 (RDL 10/2015, de 11 de septiembre) se aprobó la posible cancelación de deudas con la AEAT y la TGSS, que se estaban compensando mediante retenciones de la participación en tributos del Estado, mediante la formalización de préstamos. También, en esa misma norma se recoge la concesión de anticipos extrapresupuestarios equivalentes, como máximo al importe anual de las entregas a cuenta de la participación en tributos del Estado de 2015. Esa financiación extraordinaria se sustituyó por préstamos con el Fondo de Ordenación citado en junio de 2016. Las dos últimas medidas estaban diseñadas para que optaran a ellas determinados ayuntamientos con una situación de riesgo financiero. 
Mediante el Real Decreto-ley 17/2014, de 26 de diciembre como señala (Carpio; 2015), se ha creado el Fondo de Financiación a Entidades Locales con dos compartimentos: Fondo de Ordenación (para EELL en situación de riesgo financiero o que no pueden refinanciarse en condiciones de prudencia financiera) y Fondo de Impulso Económico (para EELL saneadas financieramente) con una dotación de 1.000 millones de euros para cada uno de los años 2015 y 2016, y se prevé en igual importe para 2017. Se ha posibilitado la inclusión de la financiación de la ejecución de sentencias judiciales firmes mediante la disposición adicional primera de la Ley Orgánica 6/2015, de 12 de junio, de modificación de la Ley Orgánica 8/1980, de 22 de septiembre, de financiación de las Comunidades Autónomas y de la Ley Orgánica 2/2012, de 27 de abril, de Estabilidad Presupuestaria y Sostenibilidad Financiera.

De esos importes, según indica el Ministerio de Hacienda y Función Pública, se aprueba la disposición por las entidades locales de 820,3 M€ en 2015, de 749,7 M€ en 2016 y se ha aprobado un importe de 643,2 $\mathrm{M} €$ en 2017. En total los ahorros generados por los préstamos con los Fondos citados se eleva a 1.069,8 $M €$. También, se posibilita el aumento en 3 años del período de carencia y de amortización de los préstamos formalizados entre 2012 y 2016 con el FFPP y el Fondo de Ordenación por determinados ayuntamientos con problemas financieros lo que posibilita, de facto, una nueva actuación para dotar de una mayor margen de liquidez a estas entidades.

CUADRO 7. EVOLUCIÓN DE LA PARTICIPACIÓN DE LAS ENTIDADES LOCALES EN LOS TRIBUTOS DEL ESTADO. PERIODO 2017-2011

\begin{tabular}{lrrr}
\hline \multicolumn{1}{c}{ Financiación de las entidades locales } & PGE 2017 & PGE 2011 & $\boldsymbol{\Delta}$ (\%) \\
\hline Entregas a cuenta Municipios (modelo general o de variables) & $4.478,09$ & $3.913,26$ & 14,4 \\
\hline Entregas a cuenta Municipios (modelo de cesión) & $6.002,19$ & $5.014,27$ & 19,7 \\
\hline Entregas a cuenta Provincias y entes asimilados & $5.049,84$ & $4.293,89$ & 17,6 \\
\hline Entregas a cuenta cesión de impuestos estatales & $1.728,62$ & $1.522,66$ & 13,5 \\
\hline Liquidación definitiva de ejercicios anteriores (año n-2) & 710,16 & 0,00 \\
\hline $\begin{array}{l}\text { Reintegros de liquidaciones de 2008 y 2009 (estimación fraccionamiento } \\
\text { en 240, 120, 108 o 60 mensualidades) }\end{array}$ & $-271,88$ & $-305,15$ & 10,9 \\
\hline Total presupuesto inicial & $17.697,02$ & $14.438,93$ & 22,6 \\
\hline
\end{tabular}

Fuente: elaboración propia a partir de datos del Ministerio de Hacienda y Función Pública

En todos los casos de medidas de apoyo a las entidades locales, se ha venido aplicando una condicionalidad que se ha plasmado en los planes de ajuste. Ésta condicionalidad en su grado de mayor intensidad requiere la aplicación de medidas de reducción de los gastos de funcionamiento; financiación adecuada de servicios públicos, de forma que en tres años se autofinancien, y supresión de servicios no obligatorios; no se pueden suprimir tributos exigidos con anterioridad; sólo pueden aprobar medidas de incremento global de cuotas íntegras de cada tributo local; la aplicación de beneficios fiscales obligatorios; tienen prohibida la aplicación de tipos de gravamen reducidos en el Impuesto de Bienes Inmuebles; y no pueden constituir ni participar en entidades dependientes y deben reducir su sector público (Calvo; 2014), (Ruiz; 2017), (Carpio; 2015), (González; 2014), (Angoitia y Tobes, 2014).

\section{CONCLUSIONES Y DISCUSIÓN}

En el marco del análisis realizado, es evidente el cambio de escenario respecto al inicial de 2012. Los factores que han permitido el cambio de la situación financiera son, por un lado, el mayor grado de responsabilidad de las corporaciones locales en la gestión financiera, que se pone de manifiesto en la adopción de medidas de política fiscal restrictiva tanto por el lado del gasto, contrayéndolo, como por el del ingreso, incrementándolo, si bien en el ámbito jurídico definido a partir de la Ley Orgánica de Estabilidad Presupuestaria y Sostenibilidad Financiera muy diferente al anteriormente existente, propicia, cuando no exige, la adopción de aquellas actuaciones. 
Por otro lado, el cambio de situación financiera también se ha debido a la adopción de medidas de apoyo financiero, que han permitido que un buen número de entidades locales que presentaban desequilibrios financieros los hayan podido corregir, con el impacto positivo que se ha derivado para el subsector en su conjunto.

No obstante, es necesario identificar los retos a los que se enfrentan las entidades locales y también, como regulador, el Estado. Así, se debe tener en cuenta la heterogeneidad de las entidades locales y la diversidad de sus estructuras financieras, como hemos visto. En consecuencia, el primer reto es el establecimiento de un marco jurídico que regule a diversas entidades locales con diferentes estructuras financieras y distintas competencias.

El siguiente reto es posibilitar que determinados municipios puedan reconducir su situación financiera, superando, en un buen número de casos, los problemas de gobernabilidad que se han presentado en corporaciones locales con gobiernos en minoría y que, por esta circunstancia, no consiguen aprobar medidas de consolidación fiscal ni planes de corrección de desequilibrio ni siquiera la solicitud a la Administración del Estado de medidas de apoyo financiero. Esta medida ya fue incluida en la reforma local de 2013, pero tras sentencia en contra del Tribunal Constitucional, en aras de proteger el principio de autonomía local, finalmente, no fue aplicada. Además, una medida necesaria en relación con esos ayuntamientos, sería la conversión de deuda a corto plazo en largo plazo. En definitiva, nos encontramos ante un reto normativo y otro «político» u organizativo.

Además, hay otros retos que pasan por la profundización de las medidas ya adoptadas y por la posible mejor articulación de otras, orientadas todas ellas a mantener la posición financiera saneada que presenta el subsector de las corporaciones locales.

En este sentido no debemos obviar las modificaciones que deberían introducirse en el ámbito tributario y que van a venir impuestas bien por la realidad existente y los efectos derivados de la actual normativa contenida en el texto refundido de la Ley reguladora de las Haciendas Locales, bien por la jurisprudencia constitucional. En ese contexto, hay que tener presente las posibles mejoras de la regulación de las tasas o la necesaria reforma de la regulación del impuesto sobre el incremento del valor de los terrenos de naturaleza urbana. Consiste el reto en el ámbito financiero en definir modelos de participación en tributos del Estado que teniendo presente el cumplimiento del principio de suficiencia financiera proporcionen recursos adecuados para la financiación de las competencias propias de las entidades locales. En este sentido, es importante que las comunidades autónomas asuman la obligación contenida en el artículo 142 de la Constitución y establezcan sistemas de participación en sus ingresos de las entidades locales de sus respetivos territorios. En el ámbito presupuestario cada vez se hace más necesario conciliar las normas contenidas en el texto refundido de la Ley reguladora de las Haciendas Locales con la normativa de estabilidad presupuestaria y sostenibilidad financiera. Actualmente existe una brecha regulatoria entre ambas normas que es preciso solventar para evitar los problemas interpretativos que se están produciendo. Precisamente, para analizar y proponer líneas de reforma del sistema de financiación local, y los aspectos financieros, tributarios y presupuestarios de la Ley reguladora de las Haciendas Locales, la constitución y conclusiones del trabajo de una Comisión de expertos para la revisión del sistema de financiación local es una buena noticia para abordar una posible reforma normativa.

La permanente adaptación a las circunstancias y excepcionalidades de una estructura heterogénea como es la que caracteriza a la planta municipal española conlleva un reto de continua adaptación necesario para responder a las necesidades de los ciudadanos. Además, un mayor consenso en términos políticos y doctrinales sobre la normativa competencial a desarrollar y la financiación asociada ayudaría a alcanzar esos objetivos de una manera más certera y rápida.

\section{BIBLIOGRAFÍA}

ACíN, A. (2016): "Hacienda local. Algunas urgencias para la reforma de la ley de haciendas locales". La administración práctica: enciclopedia de la administración municipal, núm. 4, págs. 67-76.

ALGARRA, A.; ROMERA, O. (2015): "Una reflexión sobre los resultados obtenidos por la Administración local en el marco de la reforma del artículo 135 de la Constitución Española". Revista de Estudios de la Administración Local y Autonómica. Nueva época, núm. 3. https://doi.org/10.24965/reala.v0i3.10242.

AGUILAR, F. (2016): Los impuestos locales en España: situación actual y perspectiva de futuro. Tesis doctoral. Universidad de Málaga.

ALONSO, M. (2013): “El procedimiento de regularización catastral 2013-2016: el reconocimiento legal de la deficiente inspección catastral y tributaria del IBI”. Tributos locales, núm. 110, págs. 63-80. 
ÁLVAREZ, A. (2012): "La reforma de la fiscalidad local (II)". Revista tributaria oficinas liquidadoras, núm. 34, págs. 65-73.

ANGOITIA, M.; TOBES, P. (2014): "La financiación local en el contexto de la Ley 27/2013 de racionalización y sostenibilidad de la Administración local". Estudios sobre el sistema tributario actual y la situación financiera del sector público: Homenaje al Profesor Dr. D. Javier Lasarte Álvarez, págs. 1.229-1.252.

ANTONIO, P. (2015): "La desigualdad económica avanza en España: Informe del INE y FAES alertan de la creciente brecha social". El siglo de Europa, 1.117, págs. 58-60.

ARENILLA, M. (2014): "Principios de la reforma local". CUNAL - Revista de Estudios Locales, núm. 169, págs. 8-37.

ARENILLA, M.; PÉREZ, P. y ROMERA, Ó. (2014): "El impacto de la reforma local española en los servicios sociales" en Tirant monografrías, ed. Sostenibilidad financiera y administración local. Un estudio comparado. Valencia. Tirant lo Blanch, págs. 185-259.

ARIZA, J. (2013): "Sobre los efectos políticos de la desigualdad". Temas para el debate, núm. 218-219, págs. 23-24.

ARRIETA, J. (2010): "La participación en los Tributos del Estado". Los tributos locales, págs. 977-1.011.

BARRAGUÉ, B. (2011): "Desigualdad económica y bienestar: tres modelos de justicia social". Cuadernos electrónicos de filosofía del derecho, 23, págs. 17-46.

BAZA, J. (1997): "La hacienda local y su transformación: rasgos estructurales de las finanzas municipales en Castilla y León (1981-1996)". Anales de estudios económicos y empresariales, págs. 171-202.

BLANCO, F. J. y CALLEJÓN, J. (2014): "Cobertura de la dependencia a nivel europeo". Anales de economía aplicada, ASEPELT España, págs. 112-124.

BERDÚN, P. (2001): “Intervencionismo y gasto público en Europa, 1870-1920”. Acciones e investigaciones sociales, 13, págs. 235-291. https://doi.org/10.26754/ojs_ais/ais.200113210.

BERZOSA, C. (2013) "Desigualdad y conflicto social”. Temas para el debate, 218-219, págs. 20-22.

BLYTH, M. Y E. Lonergan (2014): "Print less but transfer more", Foreign Affairs, 93 (5), págs. 98-109.

BOIX, A. (2017): "El régimen local tras el fracaso de la reforma 2013". El cronista del Estado Social y Democrático de Derecho, núm. 68, págs. 24-35.

CALVO, V. (2014) "Las modificaciones que afectan a la gestión económico financiera de las entidades locales en materia de endeudamiento, deuda comercial, estabilidad, registro de facturas y factura electrónica". Reforma del Régimen Local: la Ley de Racionalización y Sostenibilidad de la Administración Local: veintitrés estudios, págs. 827-874.

CAMPOS, M. C. (2016): "Una proyección de futuro: retos de las entidades locales ante el nuevo marco normativo y medidas para garantizar su cumplimiento". El nuevo procedimiento administrativo local tras la Ley 39/2015, págs. 847-874.

CAVERO, T. (2014) "Desigualdad y fiscalidad van de la mano". Razón y fe: Revista hispanoamericana de cultura, tomo 270, núm. 1.391, págs. 153-163.

CARDONA, J. (2017): "Plusvalía municipal: necesidad de reforma urgente". Actualidad jurídica Aranzadi, núm. 929, pág. 21.

CARPIO, M. (2015): "El Real Decreto-ley 17/2014, de 26 de diciembre, de medidas de sostenibilidad financiera de las Comunidades Autónomas y Entidades Locales y otras de carácter económico". Consultor de los ayuntamientos y de los juzgados: Revista técnica especializada en administración local y justicia municipal, núm. 2, págs. 149-156.

CARRO, J. L. (2017): "La reforma del régimen local en 2013: consideraciones introductorias". Derecho local de Galicia, págs. 27-79.

CHICO, P. (2010): "Las tasas municipales: nuevas oportunidades para su establecimiento como recurso ordinario de financiación de las Corporaciones Locales". Tributos locales; núm. 97, págs. 115-166.

CHINCHILLA, J. A.; DOMÍNGUEZ, M. (2015): "Los servicios públicos locales: reforma de la Administración local en tiempos de crisis económica". Revista Digital de Derecho Administrativo. núm. 14, págs. 45-63. https://doi. org/10.18601/21452946.n14.05.

CRESPO, J.; JIMÉNEZ, B.; Martí, A; MORAGUES, M. J..; SORIANO, R. (2010): "El déficit de las Entidades locales. Algunas medidas para reducirlo". Consultor de los ayuntamientos y de los juzgados: Revista técnica especializada en administración local y justicia municipal, núm. 17, págs. 2.557-2.572.

DE ARRIBA, R. y KIRBY, P. (2014): Crisis en la periferia europea: política económica e impacto social en España e Irlanda, págs. 63-86.

DELAUNAY, B. (2014): "Crisis financiera y deuda de las entidades locales en Francia”, págs. 281-294.

DELGADO, A. (2017): "Las sanciones catastrales y tributarias en relación con el impuesto de bienes inmuebles: necesidad de reforma urgente". Tributos locales, núm. 128, págs. 65-77.

DOMÍNGUEZ, M. (2014): "Presente y futuro de la administración local en España". Nuevas políticas públicas: Anuario multidisciplinar para la modernización de las Administraciones Públicas, núm. 9, págs. 41-51.

DOMÍNGUEZ, J. M. y LÓPEZ, J. M. (2012): "La reforma de la política presupuestaria en España: análisis de la Ley Orgánica de Estabilidad Presupuestaria y Sostenibilidad Financiera”. Instituto Universitario de Análisis Económico y Social. Documentos de trabajo, 9.

DOMÍNGUEZ, J. M. (2014): “Tamaño del sector público y redistribución efectiva”. eXtoikos, 13, págs. 57-59.

DURÁN, F. J. (2015): Reforma y financiación de la administración local en España: una propuesta desde la estrategia del norte de Europa. Tesis doctoral. Universidad Pontifica de Comillas. 427 pp. 
EDO, V. (2011): "La gestión presupuestaria del gasto del Estado: un análisis de las desviaciones presupuestarias desde las perspectivas económica y de programas". XVIII Encuentro de Economía Pública. Málaga, 46 pp.

ESCRIBANO, G. (2011): "Nueva energía y amenazas en el Mediterráneo". Economía Exterior, 57, págs. 147-157.

EZQUIAGA, I. (1995): “Tutela, gestión financiera y estructura de la deuda local”. Economistas, núm. 65, págs. 47-59.

FEDEA (2016): "La desigualdad en España: una visión a largo plazo". Workshop sobre la desigualdad de la renta en España. Madrid, 4 de julio de 2016.

FERNÁNDEZ, T. y ANDRÉS, S. (2015): "Crisis y Estado de bienestar: las políticas sociales en la encrucijada". Tendencias \& Retos, 20 (1), págs. 119-132.

FERNÁNDEZ, G. R. (2015): “Las finanzas locales y el planeamiento: ¿suficiencia fiscal contra racionalidad urbanística?, núm. 252, págs. 31-33.

FONT I LLOVET, T.; GALÁN, A. (2014): "Los retos actuales del gobierno local: repolitización, diversificación e interiorización". Anuario de gobierno local, núm. 1, págs. 11-42.

FONT I LLOVET, T.; GALÁN, A. (2012): "Racionalización y sostenibilidad de la Administración local: ¿es esta la reforma?". Anuario del Gobierno Local, núm. 1, págs. 11-43.

FUENTETAJA, J. A. (2015): Función pública local y reforma local, núm. 37, págs. 41-75.

FUERTES, F. J. (2016): "La reforma de la LBRL por la Ley 27/2013 en el Tribunal Constitucional". Cunal - Revista de estudios locales, núm. 189, págs. 36-53.

GARCÍA, A. (2016): "Hamburguesas y eficiencia. Del estado del bienestar a la sociedad del bienestar". Gestión y análisis de políticas públicas, 15, 13 pp. https://doi.org/10.24965/gapp.v0i15.10311.

GARCÍA, J. F. (2014): "Las nuevas medidas de apoyo a la financiación de las Entidades Locales". Tributos locales, núm. 114, págs. 53-68.

GOERLICH, F. J.; MAS, M. y PÉREZ, F. (2002): "Concentración, convergencia y desigualdad regional en España". Papeles de economía española, 93, págs. 17-36.

GONZÁLEZ, M. (2010): "Participación de los entes locales en los tributos del Estado y de las Comunidades Autónomas. Las subvenciones". La proyectada reforma de las Haciendas Locales (recurso electrónico), págs. 7-25.

GONZÁLEZ, A. M. (2014): "Deuda comercial en las Corporaciones Locales: guía para el control y seguimiento conforme a Ley Orgánica 9/2013, de 20 de diciembre, de Control de la Deuda Comercial en el Sector Público". Consultor de los ayuntamientos y de los juzgados: Revista técnica especializada en administración local y justicia municipal, núm. 20, págs. 2.106-2.115.

GONZÁLEZ-RODRÍGUEZ, M. R.; VELASCO, F.; GONZÁLEZ-ABRIL, F. L. (2010): "La eficiencia del sistema de protección social español en la reducción de la pobreza". Papeles de población, vol. 16, núm. 64.

HERNÁNDEZ DE COS, P.; y PÉREZ, J. J. (2015): "El impacto de los salarios y el empleo público. Una perspectiva macroeconómica". Presupuesto y Gasto Público, 79, págs. 11-26.

IBARRA, A. (2017): "La plusvalía municipal STG de 17 de febrero 2017". Cont4b/3, núm. 61, págs. 30-32.

KARLSDOTTER, K.; NAVARRO, C.; MARTÍN, J. J. y LÓPEZ DEL AMO, M. (2011): "Análisis multinivel de la renta y las desigualdades en renta y salud en España”. XVIII Encuentro de economía pública, 2011. Málaga.

LAGO, S. y MARTÍNEZ, J. (2016): "El gasto público en España en perspectiva comparada ¿gastamos lo suficiente? ¿gastamos bien?". Papeles de economía española, 147, págs. 2-25.

LÓPEZ, R. (2013b): "La economía sumergida en España”, eXtoikos, 10, págs. 63-66.

LÓPEZ, R. (2014): “La relación entre la distribución de la renta y de la riqueza en España”, eXtoikos, 13, págs. 53-54.

LORENZO, F. y RENES, A. (2013): "Pobreza y exclusión social en España: ¿continuidad en las tendencias o cambio cualitativo en la estructura de la sociedad? Temas para el debate, 218, págs. 54-57.

LOZANO, B.; VÁZQUEZ, C. (2012): "El mecanismo extraordinario de financiación para el pago a proveedores de las entidades locales: (Reales Decretos Leyes 4/2012 y 7/2012). Diario La Ley, núm. 7.840.

MARTENS, H. (2009): “¿Salir de la crisis?: Una política económica para la UE”. Política Exterior, vol. 23, 132, págs. 21-26.

MARTíN, L. (1984): “La administración local”. España: un presente para el futuro, vol. 2, págs. 267-282.

MARTÍNEZ, C. (2017): "La imposibilidad de exigir tasas por determinados servicios públicos locales: un estudio del art. 21 TRLHL”. Tributos locales, núm. 128, págs. 47-64.

MASSA, G. (2015): "Gasto público, PIB y crisis económica. Un análisis comparado". Revista de derecho constitucional europeo, 23, $26 \mathrm{pp}$.

MERINO, V. (2016): “¿Qué fue de la reforma local?”. Cunal - Revista de estudios locales, núm. 190, págs. 12-33.

MOCHÓN, L. (2012): "La reforma del artículo 135 de la Constitución española y la subordinación de la deuda pública a la estabilidad presupuestaria y sostenibilidad financiera". Civitas. Revista española de derecho financiero, núm. 155, págs. 99-137.

MONTSERRAT, J. (2015): "Impactos de las medidas de estabilidad presupuestaria en el Sistema de Autonomía y Atención a la Dependencia: retos de futuro”. Zerbitzuan: Gizarte zerbitzuetarako aldizkaria, 60, págs. 9-30.

MOLINA, A.; GUARNIDO, A. y AMATE, I. (2013): "Los efectos redistributivos del gasto público en la Unión Europea". eXtoikos, 9, págs. 11-20.

MUÑOZ DE BUSTILLO, R. (2013): “La gran brecha: desigualdad personal de la renta en España”. Temas de debate, 218-219, págs. 25-28. 
MUÑOZ, S. (1981): "La distribución de competencias entre el estado, las comunidades autónomas y las corporaciones locales en materia de medioambiente". Documentación administrativa, núm. 190, págs. 351-382.

NAVARRO, A. (2016): "La reforma de la Hacienda Local: la necesaria atención a la diversidad tipológica de Municipios". Documentos -Instituto de Estudios Fiscales-, núm. 14, págs. 71-77.

NAVARRO, V. (2009): "Protección social y eficiencia económica: el caso de EE.UU”. Temas para el debate, 179, págs. 26-28.

OCHANDO, C. (2010): "La distribución de la renta en España en el periodo de crecimiento económico: 1998-2005". Estudios de economía aplicada, vol. 28, 3, pág. 691.

ORTEGA, M. P. (2016): "Aspectos económicos en la reforma de la actividad administrativa: en busca de la eficiencia y su control”. Cunal - Revista de estudios locales, núm. 191, págs. 146-158.

PAREJO, L. J. (1981): Garantía institucional y autonomías locales. Instituto de Estudios de Administración Local.

PEDRAJA, F. M. y SUÁREZ, J. (2011): "Financiación municipal: equilibrios, especialización e incentivos". Revista española de control externo, núm. 38, págs. 15-42.

PEDRAJA, F. M. y SUÁREZ, J. (2015): "La arquitectura del sistema descentralizado en España: Comunidades Autónomas y Corporaciones Locales". Papeles de economía española, núm. 143, págs. 15-27.

PÉREZ, V. (2015): La autonomía local: luces y sombras de la aplicación de un principio vertebrador del Estado. Tesis doctoral. Universidad de Sevilla. $541 \mathrm{pp}$.

PONS, M. (2011): "Estudio cuantitativo de la participación de los municipios en los tributos del Estado para el periodo 2004-2010, la liquidación definitiva del año 2009”. Cunal - Revista de estudios locales, núm. 145, págs. 28-43.

PORRAS, A.-M. (2013): La gobernanza multinivel del gasto público europeo. Tesis doctoral. Universidad de Sevilla, Sevilla, pág. 556.

QUIROGA, A.; NAVARRO, V. (2003): "La protección social en España y su desconvergencia con la Unión Europea". Revista de ciencias sociales, 177 , págs. 3-37.

ROBLES, M. (2014): "La reforma local del PP ataca una parte del Estado democrático: los Ayuntamientos: no se soluciona un tema fundamental: la financiación de las Haciendas Locales". Temas para el debate, núm. 232, págs. 30-32.

ROMERA, Ó. (2016): "El funcionamiento de las diputaciones provinciales en nuestro modelo territorial". Cuadernos de derecho local, núm. 41, págs. 255-325.

ROMERA, Ó.; CUTRÍN, M. (2014): “Comentarios a la Reforma de la Administración Local”. Cunal - Revista de estudios locales, núm. 168, págs. 28-50.

RUIZ, J. M. (2017): "El endeudamiento local a debate". Papeles de trabajo del Instituto de Estudios Fiscales. Serie economía, núm. 4, págs. 5-56.

RUIZ, M. (2016): "Una nueva reforma de la Ley General Tributaria sin la participación de las entidades locales". Tributos locales, núm. 125, págs. 10-27.

RUIZ-RICO, C. (2016): "El impacto de la integración europea en el actual modelo de gobernanza local". Revista general de derecho constitucional, núm. 23.

RUSSINÉS, J. (1985) "Esfuerzo fiscal y participación en los ingresos estatales de los municipios madrileños". Alfoz: Madrid, territorio, economía y sociedad, núm.18-19, págs. 51-56.

SANTAMARÍA, J. A. (1982): Las administraciones territoriales, la administración institucional. Universidad Complutense.

SÁNCHEZ, A. y NAVARRO, M. V. (2014): "La desigualdad en los países desarrollados: cohesión y bienestar". Anales de economía aplicada 2014. ASEPELT España. Reunión anual, 2014, págs. 336-363.

SHAIKH, A. (2004): “¿Quién paga el «bienestar» en el Estado de Bienestar? Un estudio multi-países”. Apuntes del CENES, vol. 24, 38, págs. 31-50.

SUÁREZ, J. (2003): "Financiación Local y Corresponsabilidad Fiscal Local: ¿ganamos con el nuevo modelo?". Revista de estudios regionales, núm. 66, págs. 115-128.

TAMAMES, R. y GALLEGO, S. (2006): Diccionario de Economía y Finanzas. Alianza Editorial.

TRÁNCHEZ, J. M. y HERRERO, A. (2014): “¿Ha existido convergencia en el gasto social en la unión europea-15? Un análisis para el periodo 1995-2010". XXI Encuentro Economía Pública, 2014, 23 pp.

VALLE, J. L. (2010): "La reforma de la contabilidad local". Consultor de los ayuntamientos y de los juzgados: Revista técnica especializada en administración local y justicia municipal, núm. 15-16, págs. 2.362-2.384.

VEIRA, J. L. (2013): Desigualdad y capital social en España. Oleiros: Netbiblo. 2013. https://doi.org/10.4272/978-8415562-23-8.

ZAFRA, J. L.; PLATA, A. M.; PÉREZ, G.; LÓPEZ, A. M. (2011): "Influencia de los factores económico-financieros, políticos y de las formas de gestión sobre el nivel de deuda viva en las entidades locales usando la metodología de datos de panel". XVIII Encuentro de economía pública. Málaga.

ZAFRA, V. (2016): “Una reforma local que empobrece la democracia”. Temas de debate, núm. 261-262, págs. 32-34.

ZAPICO, E. (2010): "Importancia y posibilidades estratégicas de la transparencia del gasto a nivel de políticas públicas". Documentación administrativa, 286-287 págs. 239-272.

ZUBIRI, I. (1995): "Financiación municipal: lecciones para España de la teoría y la experiencia internacional comparada”. Estado y economía: elementos para un debate, págs. 79-125. 